\title{
Transição para o ensino remoto de emergência no ensino superior em Portugal - um estudo exploratório
}

\section{Transition to emergency remote teaching in higher education in Portugal - an exploratory study}

Filipa Seabra

Doutora em Ciências da Educação. LE@D, Universidade Aberta - UAb.

Porto - Portugal.

filipa.seabra@uab.pt

Luísa Aires

Doutora em Ciências da Educação. LE@D, Universidade Aberta - UAb. Porto - Portugal. laires@uab.pt

António Teixeira Doutor em Filosofia. Universidade Aberta - Uab. Lisboa - Portugal. antonio.moreira.teixeira.pt@gmail.com

Resumo: A pandemia de Covid-19 teve impactos profundos no ensino superior. Em Portugal, afetou cerca de 350000 estudantes, envolvidos num processo de transição de emergência para práticas de ensino remoto. Consideramos fundamental identificar práticas adotadas pelas instituições de ensino superior nesse contexto, assim como a forma como têm sido reajustadas ao longo do tempo, e como o processo foi percecionado, quer por professores, quer por estudantes. Para tal, foi aplicado um questionário online dirigido a professores e estudantes do ensino superior presencial entre os dias 22 de abril e 12 de maio de 2020. Os resultados apontam para a adoção de uma pluralidade de estratégias de ensino, com destaque para práticas síncronas, e revistas ao longo do processo. Apesar de aspetos sensíveis como a avaliação, o envolvimento dos estudantes, as atividades práticas ou a gestão do tempo, são reconhecidas potencialidades e limitações ao processo.

Palavras-Chave: COVID-19. Ensino remoto de emergência. Ensino superior.

Abstract: The Covid-19 pandemic had profound impacts on higher education. In Portugal, it affected around 350000 students, involved in an emergency transition to remote teaching practices. We consider it essential to identify practices adopted by higher education institutions in this context, as well as how they have been readjusted over time, and how the process was perceived, both by teachers and students. To this end, an online questionnaire was applied to teachers and students of on-campus higher education between April 22 and May 12, 2020. The results point to the adoption of a plurality of teaching strategies, with emphasis on synchronous practices, which have been revised throughout the process. Despite sensitive aspects such as evaluation, student involvement, practical activities or time management, potential and limitations to the process are recognized.

Keywords: COVID-19. Emergency remote teaching. Higher education. 


\section{Introdução}

As Instituições de Ensino Superior (IES), à semelhança de outros setores a nível mundial, sofreram um forte impacto com a Covid-19. Convocadas a repensarem-se, face aos desafios da sociedade digital, nos domínios da docência, da investigação e da transferência de conhecimento, as instituições de ensino superior (IES) confrontam-se, hoje, com a urgência de uma transformação digital acelerada que dê resposta às necessidades educativas e sociais impostas pela pandemia.

Sendo esta uma problemática ampla, complexa e multifacetada, no presente texto daremos particular ênfase a uma das dimensões desta realidade: as perspetivas de professores e estudantes sobre os processos de ensino e de aprendizagem em tempos de pandemia. Pretende-se identificar respostas possíveis para as questões: Que práticas foram adotadas pelas IES neste contexto? Como têm sido reajustadas? Como foi percecionado este processo, por professores e estudantes do ensino superior? Para procurar responder a estas questões, foi desenvolvido, validado e aplicado um inquérito por questionário, online, cujos resultados foram sujeitos a análise estatística e análise de conteúdo categorial com base em categorias emergentes. Os resultados do estudo permitem, de forma preliminar, salientar a diversidade de práticas adotadas, embora com saliência para o uso de estratégias síncronas a par de trabalho individual do estudante, e a experiência de dificuldades mas também de potencialidades no processo.

\section{Da Educação a Distância ao Ensino Remoto de Emergência}

\subsection{Educação a Distância}

A Educação a Distância (EaD) é definida genericamente como um método de educação que permite aos estudantes aprenderem ao seu ritmo, em espaços à sua escolha e sem interação presencial com os professores (BATES, 2020). A separação física entre professores e alunos é superada através de processos de comunicação e de aprendizagem mediados por tecnologias e artefactos de natureza diversa.

Se este princípio é aparentemente simples, estamos, pelo contrário, perante um conceito dinâmico e aberto, complexo e contextualizado (MOORE, ANDERSON, 2003). É dinâmico e aberto porque se vai redefinindo em função das mudanças sociais, nomeadamente as mudanças tecnológicas e dos objetivos dos grupos que o pesquisam; é complexo porque, sendo um fenómeno educativo, é por natureza multifacetado, não sendo passível de ser compreendido, promovido e organizado a partir de lógicas lineares; é também contextualizado porque incorpora as especificidades dos contextos e tecnologias que medeiam o processo educativo a distância ao longo 


\section{Dialogia}

SEABRA, Filipa; AIRES, Luísa; TEIXEIRA, António. Transição para o ensino remoto de emergência no ensino superior em Portugal - um estudo exploratório

da sua evolução histórica. Assim, identificamos autores, como Moore e Kearsley (2012), que enfatizam a flexibilidade espaciotemporal do conceito, bem como as metodologias de ensino, comunicação e organização que garantam esta flexibilidade das aprendizagens, enquanto outros autores, como Peters (1983), fazem apelo à racionalização e aplicação de princípios de organização industrial no acesso ao conhecimento e à massificação e reprodução da atividade pedagógica. Atualmente as abordagens e perspetivas sobre a $\mathrm{EaD}$ são distintas porque os contextos também o são. Todavia, as diferentes correntes apresentam um conjunto de elementos comuns como: uma estrutura organizacional dedicada ao ensino a distância, o planeamento minucioso dos processos de aprendizagem, o corpo docente com formação adequada, uma infraestrutura tecnológica dedicada, com equipas especializadas para a elaboração de materiais pedagógicos.

Se na análise da $\mathrm{EaD}$ adotarmos uma lente de natureza evolutiva e histórica, observamos que, ao longo do tempo, a EaD tem sido interpretada segundo diferentes 'gerações', correntes fundadas nas fases da evolução desta modalidade educativa (BATES, 2020; TAYLOR, 1999). Impõe-se, assim, a desconstrução da $\mathrm{EaD}$ e das lógicas que a operacionalizam, através de abordagens sistémicas, complexas, perspetivando-se conhecer as relações entre as distintas dimensões que a compõem e evitando-se a procura de respostas únicas no espectro de uma disciplina individual (DANIEL, 2006; MOORE, ANDERSON, 2003; COPE, KALANTZIS, 2017).

A pandemia representou, perversamente, um momento de expansão e consolidação socioeducativa da EaD. Bates (2020) representa e analisa esta realidade num contínuo de fácil interpretação, situando em polos opostos o ensino presencial e o ensino a distância. Entre estes dois polos existe um conjunto de variantes que dão resposta às especificidades de diferentes contextos e modelos educativos (figura 1).

Figura 1 - What makes face-to-face teaching pedagogically unique - if anything?

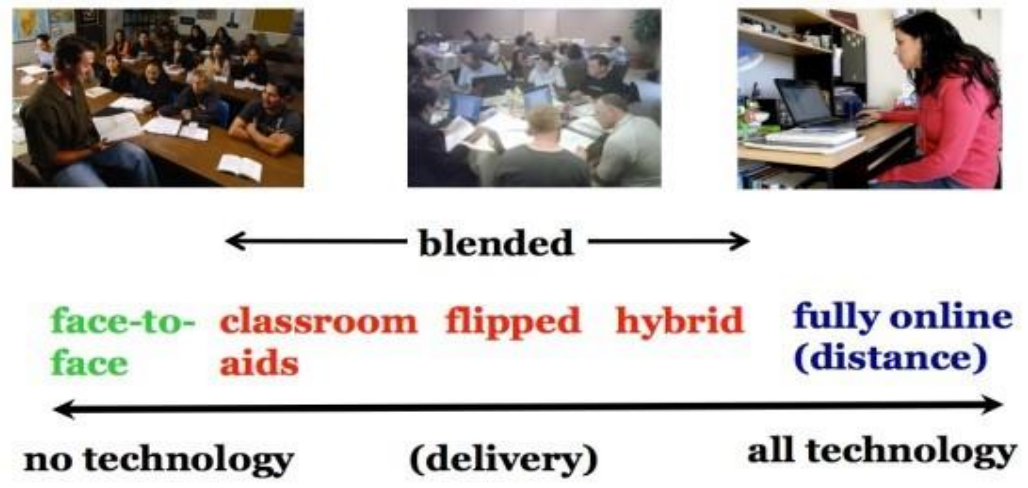

Fonte: BATES, $2020^{1}$ 
A opção por uma destas modalidades (figura 1) fundamenta-se num conjunto de prérequisitos como: a população alvo de estudantes; a área de conhecimento em causa, bem como as competências a desenvolver e os conteúdos a tratar; o tipo de tecnologias e de suportes disponíveis, sobretudo para os estudantes e docentes. A existência de uma estrutura organizativa dedicada à organização, planeamento e desenvolvimento de cursos, de docentes com qualificação específica, estruturas tecnológicas e de suporte são, entre outras, condições essenciais para a oferta de uma educação a distância de/com qualidade. A mera disponibilização de conteúdos online, a transmissão de aulas desenhadas para o ensino presencial através de tecnologias de comunicação síncrona, a primazia de conteúdos em detrimento dos objetivos e competências de aprendizagem representam, em última instância, práticas de baixa qualidade de Ensino Remoto de Emergência, não devendo portanto ser confundidas como práticas de Educação ou de Ensino a Distância. Pelo contrário, a EaD promove, antes de mais, a participação, a responsabilidade, flexibilidade e a autonomia nos percursos de aprendizagem dos alunos (BOZKURT, SHARMA, 2020).

\subsection{Ensino Remoto de Emergência}

O ensino remoto de emergência (ERE) agrega um conjunto de práticas de ensino temporárias que tentam reproduzir o ensino presencial ou o ensino mediado por tecnologias, desejavelmente de forma criativa, em consequência de um contexto de crise particular, neste caso, a Covid-19 (HODGES, MOORE, LOCKEE, TRUST, BOND, 2020). Esta expressão adquiriu maior visibilidade com o início da pandemia, em resposta à dissonância provocada pelo uso da expressão Educação a Distância em circunstâncias e práticas de ensino que não se enquadram nesta última modalidade educativa. Ao contrário do que se verifica na educação a distância, no ensino remoto de emergência, a criação de um sistema sólido, com modelos pedagógicos específicos, estruturas organizativas, design pedagógico e equipas dedicadas, não constitui uma prioridade. Em situações de emergência a prioridade reside em proporcionar o acesso ao ensino de uma forma rápida, temporária, criativa e nas circunstâncias possíveis.

Hodges, Moore, Lockee, Trust e Bond (2020) recordam que, embora sem a dimensão global associada à presente pandemia, ao longo dos tempos tem-se recorrido ao ERE a para dar resposta a situações de crise localizadas, provocadas por guerras, conflitos locais ou desastres ambientais e sanitários. Por esta razão, na senda do que propõem Bozkurt e Sharma (2020) e cientes de que a sua adoção se verifica em situações excecionais, o ERE devia ser ideado e desenhado por equipas multidisciplinares que, em conjunto, definissem as bases e prioridades desta modalidade 
de ensino. A dimensão emocional e relacional, aparentemente pouco valorizada na recente experiência de ERE que conhecemos, devia ser também uma das prioridades educativas.

A Covid-19 ainda não terminou. Por esta razão, neste estudo fazemos uma primeira abordagem a uma realidade cujas dimensões e consequências ainda não são conhecidas. Pretendemos, assim, que este seja mais um contributo para o conhecimento aprofundado desta realidade.

\section{Metodologia}

De modo a responder aos objetivos identificados, foram desenvolvidos e validados através de pré-testes acompanhados de uma reflexão falada sobre o instrumento, dois questionários, dirigidos respetivamente a professores e estudantes do ensino superior. Os questionários foram aplicados online, garantido o cuidado pelos princípios éticos que regem a investigação em educação (AERA, 2011). O instrumento foi aprovado pela Comissão de Ética do centro de investigação em que se inscreve a pesquisa.

O questionário inclui questões de resposta fechada, sujeitas a análise estatística de natureza descritiva, e questões de resposta aberta, sujeitas a análise de conteúdo categorial, com base em categorias emergentes dos dados e com recurso ao programa MaxQDA.

Os dados foram recolhidos entre os dias 22/04 e 12/05/2020. Realçamos que o fecho obrigatório das instituições de ensino foi decretado com efeitos a partir de 16 de março de 2020, pelo que os dados foram recolhidos em pleno processo de transição e adaptação das IES, concretamente entre 37 e 57 dias após o encerramento obrigatório das suas instalações físicas.

\subsection{Caracterização dos participantes}

Participaram no questionário, de forma válida, 64 respondentes, nomeadamente 26 professores e 38 estudantes do ensino superior cuja atividade anterior à pandemia decorria totalmente ou em parte, de modo presencial. Apresentam-se na tabela 1, as características desses participantes. 


\section{Dialogia}

SEABRA, Filipa; AIRES, Luísa; TEIXEIRA, António. Transição para o ensino remoto de emergência no ensino superior em Portugal - um estudo exploratório

Tabela 1 - Caracterização dos participantes

\begin{tabular}{|c|c|c|c|c|}
\hline \multirow[t]{2}{*}{ Participantes } & \multicolumn{2}{|l|}{ Professores } & Estudantes & $\mathbf{N}$ \\
\hline & \multicolumn{2}{|l|}{26} & 38 & 64 \\
\hline & \multicolumn{2}{|l|}{ Professores } & \multicolumn{2}{|l|}{ Estudantes } \\
\hline \multirow[t]{3}{*}{ Género } & Masculino & 4 & Masculino & 32 \\
\hline & Feminino & 21 & Feminino & 6 \\
\hline & Prefere não responder & 1 & & \\
\hline \multirow[t]{7}{*}{ Idade } & $26-35$ anos & 1 & $17-21$ anos & 14 \\
\hline & $36-45$ anos & 5 & $22-26$ anos & 12 \\
\hline & $46-55$ anos & 12 & $27-31$ anos & 3 \\
\hline & $56+$ & 8 & $32-36$ anos & 2 \\
\hline & & & $37-41$ anos & 1 \\
\hline & & & $42-46$ anos & 3 \\
\hline & & & $47+$ & 3 \\
\hline \multirow{2}{*}{ Tipo de IES } & Universidade & 19 & Universidade & 30 \\
\hline & Instituto Politécnico & 7 & Instituto Politécnico & 8 \\
\hline \multirow[t]{2}{*}{ Sistema } & Público & 26 & Público & 27 \\
\hline & Privado & 1 & Privado & 11 \\
\hline \multirow[t]{5}{*}{ Distritos } & $\begin{array}{l}\text { Porto, Braga ou Viana do } \\
\text { C. }\end{array}$ & 10 & Porto, Braga ou Viana do C. & 30 \\
\hline & & & Aveiro, Coimbra ou Leiria & 2 \\
\hline & $\begin{array}{l}\text { Lisboa, Santarém ou } \\
\text { Setúbal }\end{array}$ & 8 & Lisboa, Santarém ou Setúbal & 12 \\
\hline & Évora, Beja ou Faro & 1 & Évora, Beja ou Faro & 1 \\
\hline & Açores & 1 & $\begin{array}{l}\text { Viseu, Guarda, Castelo } \\
\text { Branco ou Portalegre }\end{array}$ & 1 \\
\hline \multirow[t]{3}{*}{ Nível de ensino } & Doutoramento & 11 & Doutoramento & 4 \\
\hline & $\begin{array}{l}\text { Mestrado / Mestrado } \\
\text { integrado }\end{array}$ & 22 & $\begin{array}{l}\text { Mestrado / Mestrado } \\
\text { integrado }\end{array}$ & 9 \\
\hline & Licenciatura & 23 & Licenciatura & 24 \\
\hline \multirow[t]{5}{*}{ Área científica } & Ciências Sociais & 19 & Ciências Sociais & 24 \\
\hline & Humanidades & 5 & Humanidades & 6 \\
\hline & $\begin{array}{l}\text { Ciências Médicas e da } \\
\text { Saúde }\end{array}$ & 1 & Ciências Médicas e da Saúde & 4 \\
\hline & Ciências Agrárias & 1 & Ciências Agrárias & 1 \\
\hline & & & Ciências Exatas & 3 \\
\hline \multirow{7}{*}{$\begin{array}{l}\text { Cargos } \\
\text { desempenhados }\end{array}$} & Reitor/Presidente de & 1 & & \\
\hline & Instituto Politécnico & & & \\
\hline & Conselho Científico & 7 & & \\
\hline & Diretor de Departamento & 3 & & \\
\hline & Diretor de C. Investigação & 3 & & \\
\hline & $\begin{array}{l}\text { Coordenador/ Vice } \\
\text { coordenador de curso }\end{array}$ & 8 & & \\
\hline & Conselho Pedagógico & 3 & & \\
\hline
\end{tabular}

Fonte: Elaboração dos autores. 


\section{Dialogia}

SEABRA, Filipa; AIRES, Luísa; TEIXEIRA, António. Transição para o ensino remoto de emergência no ensino superior em Portugal - um estudo exploratório

\section{Resultados - perspetivas de professores e estudantes}

Do processo de análise realizado, destacam-se as seguintes categorias:

Figura 2 - Categorias de análise

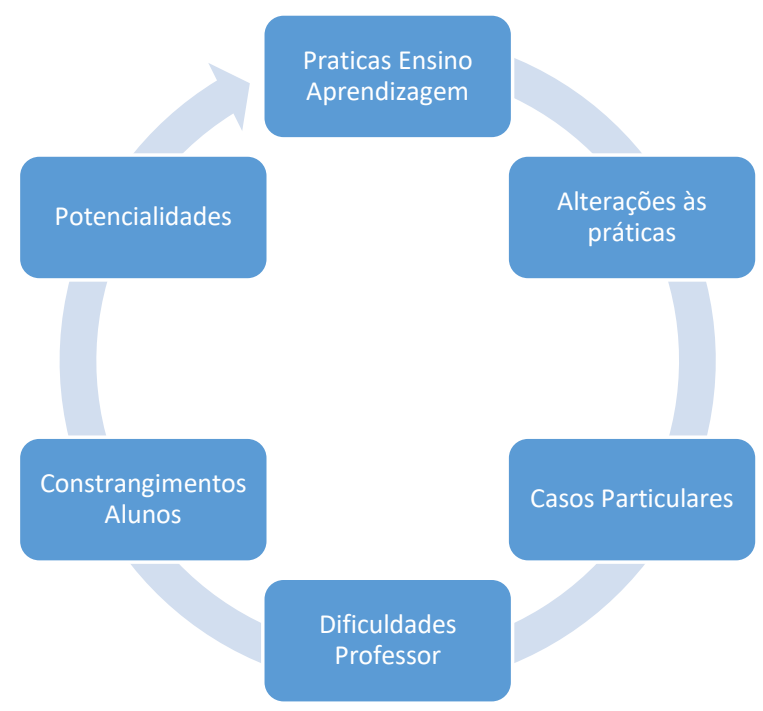

Fonte: Elaboração dos autores.

Apresentamos, de seguida, os resultados organizados de acordo com as categorias orientadoras.

\subsection{Práticas de ensino/aprendizagem adotadas}

Sistemas de gestão de aprendizagem

Quase todos os participantes identificam a plataforma de ensino a distância como o meio mais usado para envio de materiais e atividades aos estudantes (22 docentes e 36 estudantes), seguido do e-mail (13 docentes e 32 estudantes), embora também seja utilizado o telefone ou whatsapp ou similar (3 professores e 4 estudantes). Um número residual de participantes não indicou o uso da plataforma (2) e em alternativa referem-se ao uso do e-mail (1) ou do telefone/whatsapp ou similar (1).

Tempos de ensino-aprendizagem, metodologias e atividades

Em relação ao tipo e frequência dos métodos utilizados, e olhando inicialmente para as estratégias baseadas na sincronia, as respostas dos docentes revelam uma utilização pouco frequente de momentos síncronos para realizar debates ou partilhas em grupo. Inversamente, o 


\section{Dialogia}

SEABRA, Filipa; AIRES, Luísa; TEIXEIRA, António. Transição para o ensino remoto de emergência no ensino superior em Portugal - um estudo exploratório

recurso a aulas expositivas síncronas e os momentos de trabalho individual síncronos, eventualmente mais próximos de apoio tutorial, são referidos com maior frequência (Figura 3). Já os estudantes evidenciam um recurso frequente a aulas expositivas síncronas em vídeo, corroborando o referido pelos docentes. No entanto, indicam ter acesso com alguma frequência a momentos de debate em grupo, síncronos, e raramente ou nunca ter acesso a momento síncronos individuais (Figura 4).

Figura 3 - Tipo e frequência das atividades utilizadas - momentos síncronos (identificadas pelos docentes)

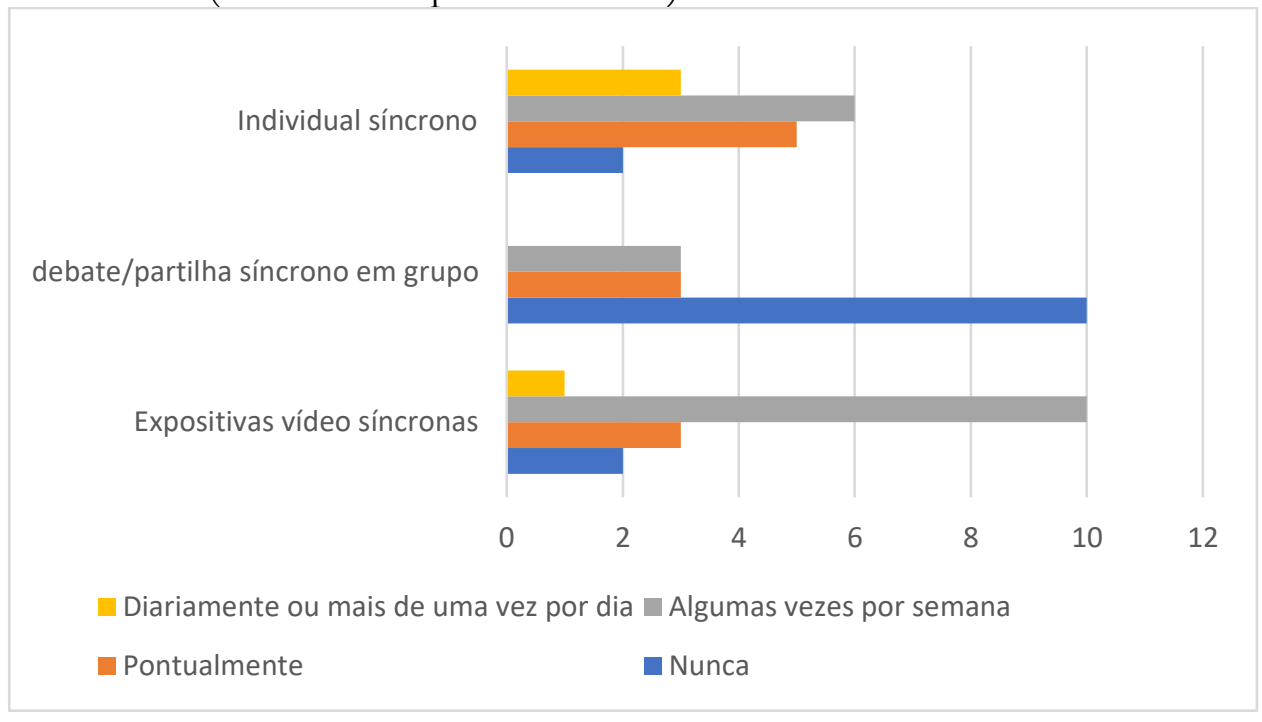

Fonte: Elaboração dos autores

Figura 4 - Tipo e frequência das atividades utilizadas - momentos síncronos (identificadas pelos estudantes)

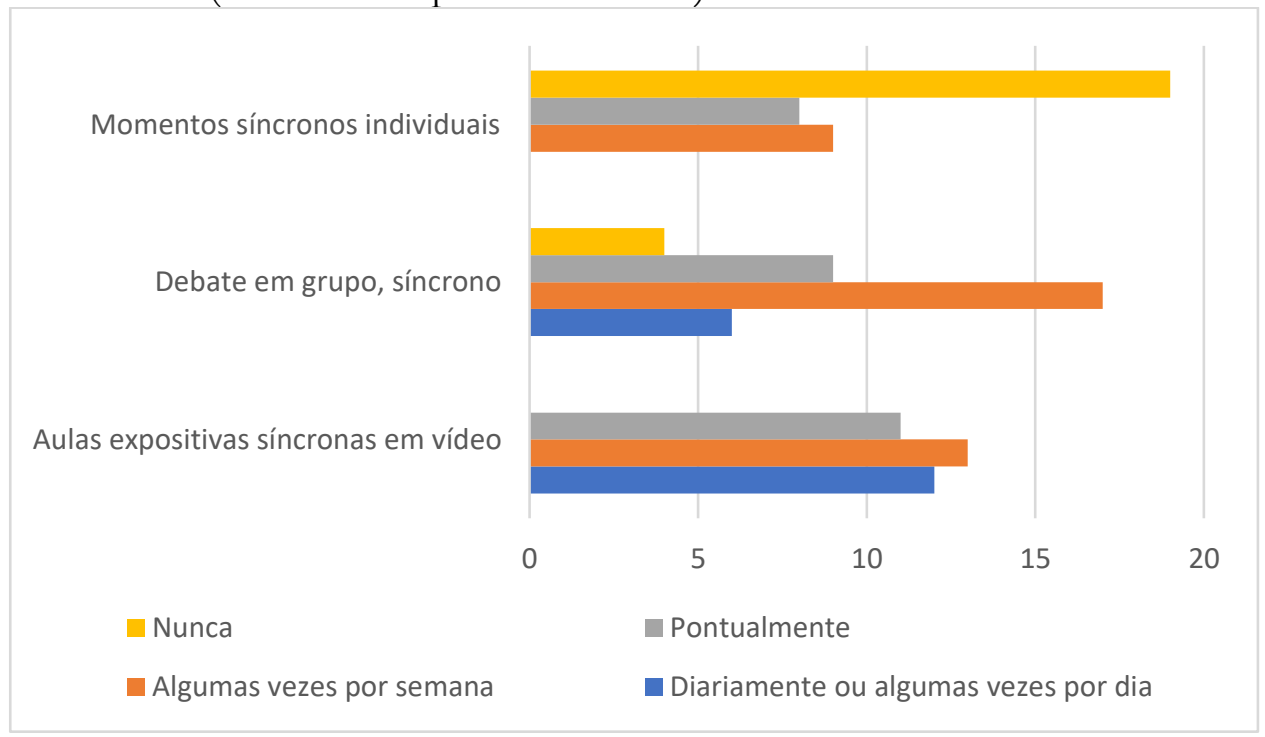

Fonte: Elaboração dos autores 


\section{Dialogia}

SEABRA, Filipa; AIRES, Luísa; TEIXEIRA, António. Transição para o ensino remoto de emergência no ensino superior em Portugal - um estudo exploratório

Por outro lado, as atividades que tendencialmente são desenvolvidas de modo assíncrono identificadas pelos docentes destacam as aulas expositivas em vídeo assíncronas, os debates assíncronos em grupo, o envio de propostas de leitura, os trabalhos inter- ou transdisciplinares, os trabalhos de pesquisa/ projeto, entre outros. O uso de materiais expositivos pré-existentes parece ser menos expressivo. A questão pedia que se identificassem todas as opções que se aplicavam, pelo que a ausência de resposta poderá sinalizar não utilização destas estratégias. O reduzido número de respostas não permite propor conclusões muito específicas, sublinhando-se sobretudo o recurso a uma pluralidade de possibilidades (Figura 5).

Figura 5 - Tipo e frequência das atividades utilizadas - momentos assíncronos (indicadas pelos docentes)

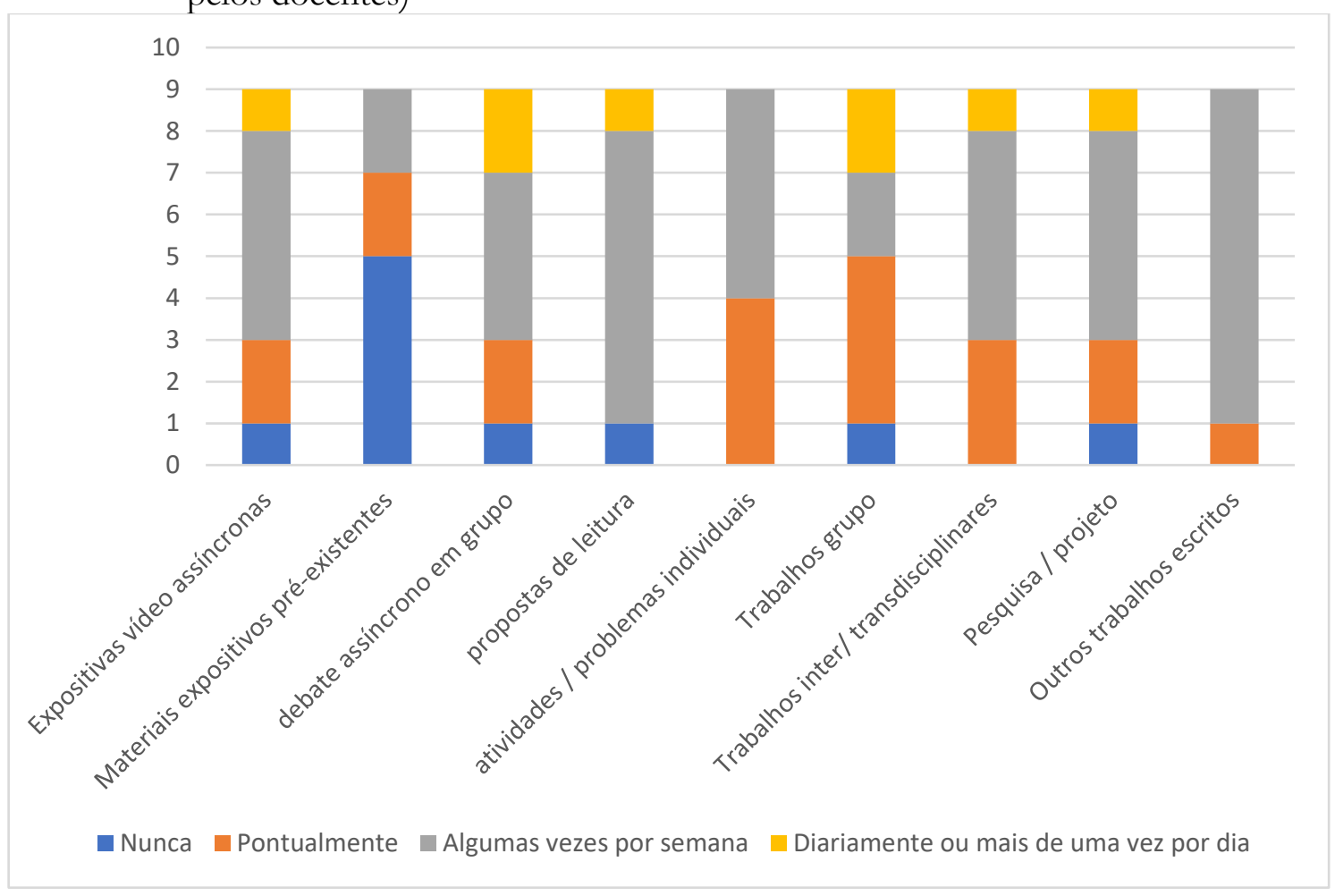

Fonte: Elaboração dos autores.

Três respondentes indicam realizar outros tipos de atividades, concretamente, atividades de avaliação online (R3), de orientação académica (R28) e de simulação (R8).

Quanto aos estudantes, as atividades que mais foram referidas ocorrer «diariamente ou algumas vezes por dia», foram tarefas individuais (13), aulas expositivas síncronas em vídeo (12), propostas de leitura (10) e outros trabalhos escritos (10). No polo inverso, os tipos de tarefas que mais foram indicadas «nunca» acontecer, foram os momentos síncronos individuais (19), as aulas 


\section{Dialogia}

SEABRA, Filipa; AIRES, Luísa; TEIXEIRA, António. Transição para o ensino remoto de emergência no ensino superior em Portugal - um estudo exploratório

expositivas em vídeo, em diferido (16), tarefas de carácter interdisciplinar (15) e debate assíncrono em grupo (9).

As respostas, evidenciadas na figura 6 apontam para um predomínio de propostas de leitura ou realização de tarefas de carácter individual pelo estudante. Existem, no entanto, respostas afirmativas a todas as questões, reiterando práticas diversificadas e heterogéneas.

Figura 6 - Tipo e frequência das atividades utilizadas - momentos assíncronos (indicadas pelos estudantes)

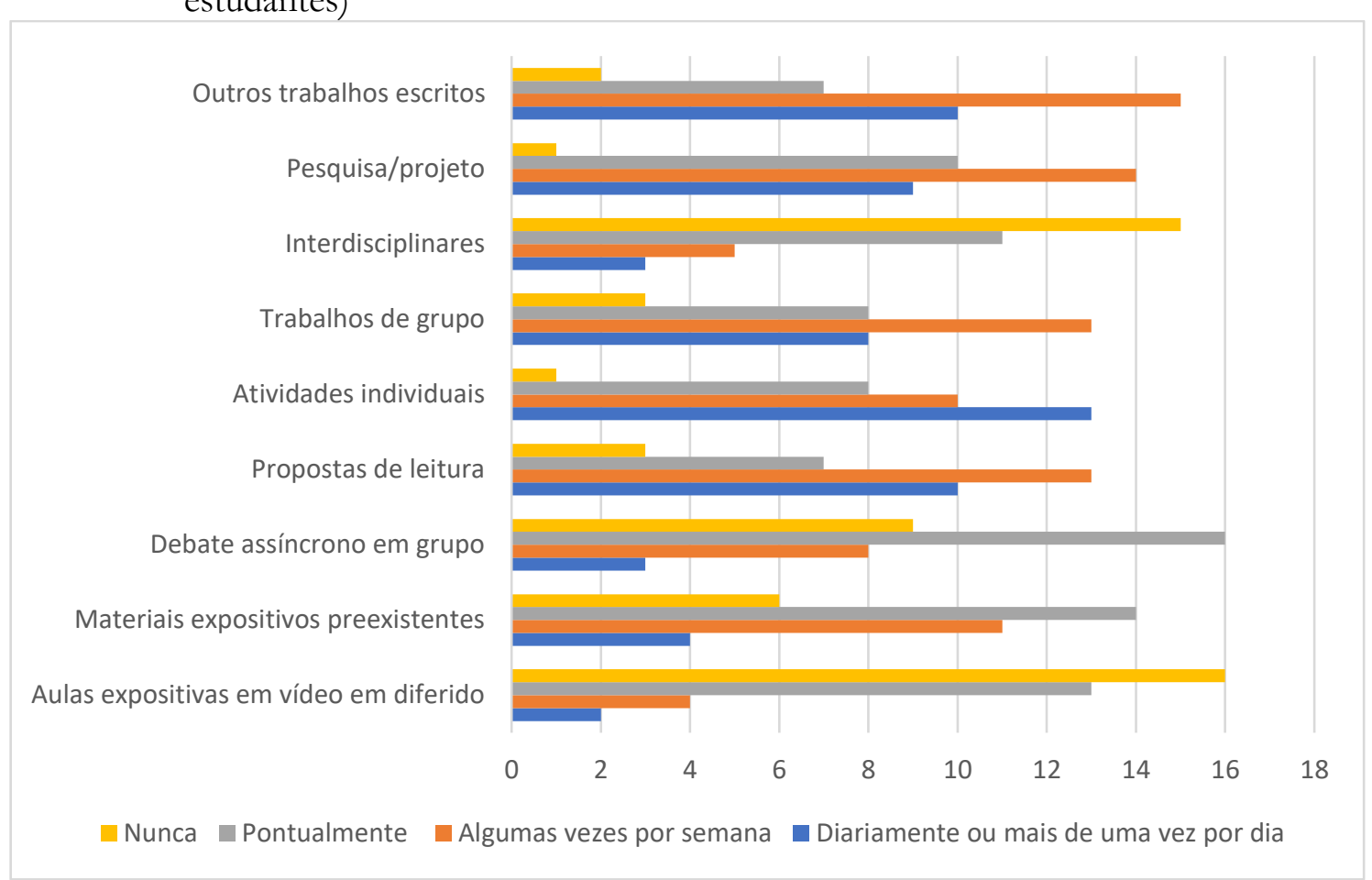

Fonte: Elaboração dos autores.

Vinte e três dos 26 professores participantes referiram dar algum tipo de feedback aos estudantes, com primazia para a correção e feedback a trabalhos escritos (20 respostas), e do feedback da participação em momentos síncronos (18 repostas).

De modo similar, a maioria dos estudantes refere ter recebido avaliação/feedback no período de ensino remoto (27 respostas afirmativas e 11 respostas negativas). Quando à forma dessa avaliação, as respostas corroboram as apresentadas pelos docentes, já que predominam a correção e feedback sobre trabalhos escritos (21) e o feedback sobre a participação em momentos de trabalho síncrono (12).

A maioria dos professores refere gastar cinco horas ou menos em atividades letivas (15 respondentes), no entanto, cinco respondentes referem gastar diariamente entre 6 e 8 horas, e três referem inclusivamente gastar 12 horas ou mais nessas atividades. Por sua vez, o número de horas 
de trabalho diárias que os estudantes consideram despender em atividades de aprendizagem a distância é muito díspar, variando entre 1 e 12 horas diárias. As respostas mais frequentes foram $4 \mathrm{~h}(6), 5,6$, e $8 \mathrm{~h}(5)$.

\subsection{Reajustes às práticas}

Dezasseis dos professores respondentes descreveram mudanças ao processo de ensino remoto, que foram implementadas já após o seu arranque. Entre estes, destacam-se referências a mudanças ao nível do currículo e avaliação ( 7 referências; ex.: "Revisão das FUC e dos métodos de avaliação" R8); e a mudanças ao nível pedagógico (6 referências), que se organizam em 3 subcategorias, respetivamente:

a) autoaprendizagem, com 4 referências (Ex.: "redução de horas de contacto e aumento de aprendizagem autónoma" R9);

b) alteração das aulas síncronas, com 3 referências (ex.: "recurso a sessões síncronas, abandono de ppt comentados assíncronos" R10; ou em sentido contrário “Alterei o (...) conteúdo das aulas em zoom, partindo do princípio que eles têm leituras que anteriormente não tinham" R4); e 1 referência a

c) alterações ao nível da orientação.

Além destas duas grandes categorias de mudanças, foi referida uma vez a existência de mudanças de natureza tecnológica, associadas à exploração das potencialidades de uma plataforma, e um outro docente referiu que estavam planeadas mudanças a implementar brevemente.

De modo coerente com o que foi indicado relativamente à coordenação do processo de transição (SEABRA, AIRES, TEIXEIRA, 2020), a implementação das mudanças parece dever-se a fatores mais associados à iniciativa própria, com base na experiência ou acesso a informação teórica relevante (11 respostas bastante ou muito), assumindo também preponderância as orientações da IES ( 9 respostas bastante ou muito). No extremo inverso, as orientações nacionais / regionais parecem ter tido reduzido impacto. Destaca-se também a grande variabilidade das respostas, que pode ser indicativa de diferentes posturas das IES e unidades orgânicas (Figura 7). 


\section{Dialogia}

SEABRA, Filipa; AIRES, Luísa; TEIXEIRA, António. Transição para o ensino remoto de emergência no ensino superior em Portugal - um estudo exploratório

Figura 7 - Fundamentos dos reajustes ao processo

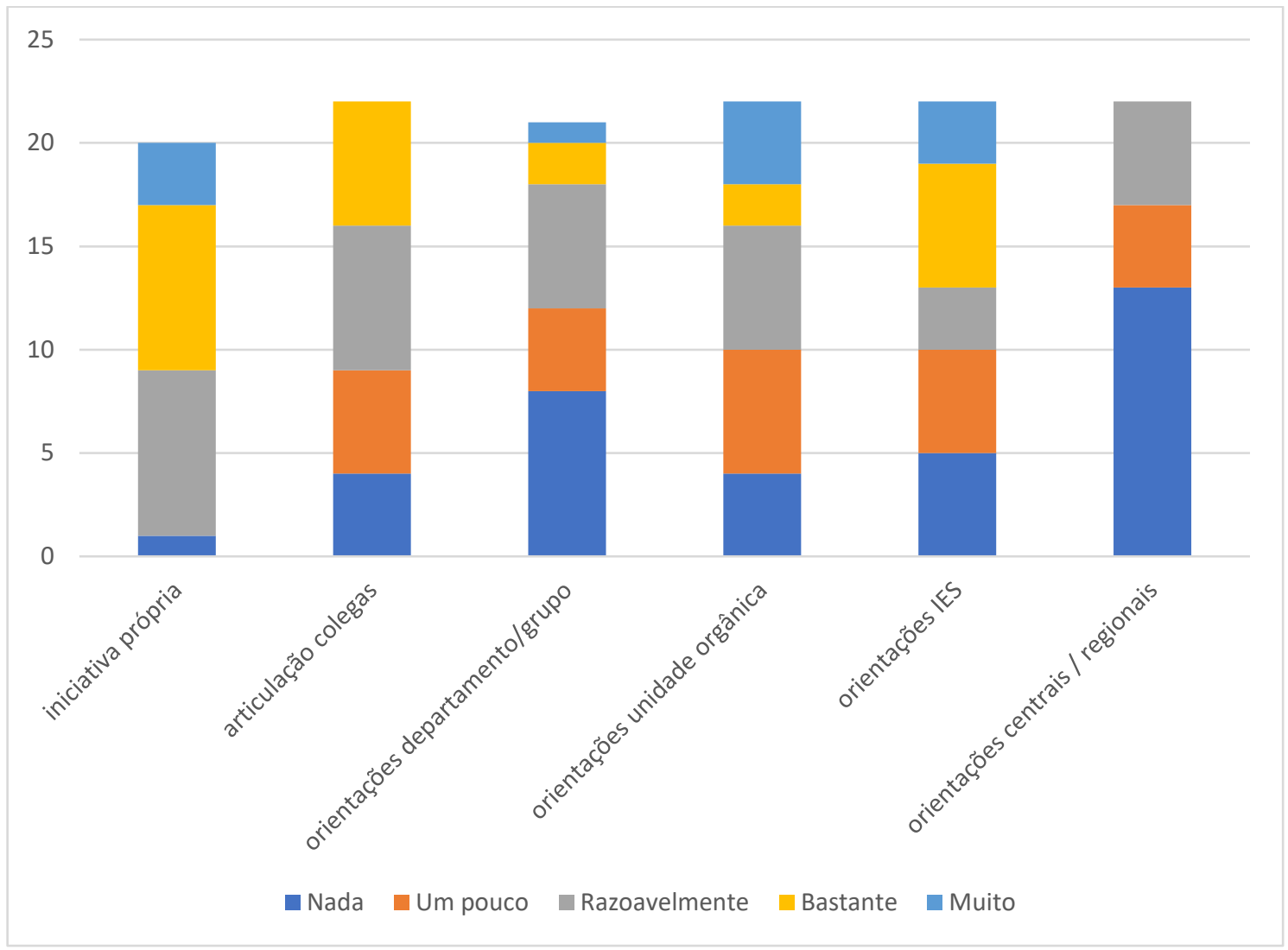

Fonte: Elaboração dos autores

Entre os estudantes, foi paritária a perceção ou não da existência de reajustes nas práticas de ensino ou avaliação já após o arranque do ensino remoto - 19 estudantes referiram a existência de ajustes, e 19 referiram não os terem verificado. $\mathrm{O}$ aspeto que mais vezes foi referido como tendo sofrido reajustes foi a avaliação, referida por 11 estudantes. Este aspeto é sentido como «pouco consensual» (E11). As limitações quanto à realização de testes escritos implicaram a adoção de outras práticas e revisão dos processos de avaliação previstos (Ex.: "substituição de testes por projectos e trabalhos de grupo" E11; "Na maiorias das unidades curriculares os testes foram substituídos por trabalhos de leitura e escrita" E28). Também foram referidas, embora com menor frequência, alterações em termos temporais (3 referências, ex.: "Alterações de horários de aula" E5), mudanças ao nível pedagógico (2 referências: Ex.: "Alteração das tarefas a desenvolver e adaptação do estágio" E13) e mudanças de natureza tecnológica (1 referência: "Mudança da plataforma zoom para blackboard” E1).

As perceções dos estudantes reforçam a importância que os docentes haviam dado às alterações em termos de avaliação, no entanto, parecem não valorizar as alterações curriculares. 


\section{Dialogia}

SEABRA, Filipa; AIRES, Luísa; TEIXEIRA, António. Transição para o ensino remoto de emergência no ensino superior em Portugal - um estudo exploratório

\subsection{Casos particulares - aulas práticas e alunos com deficiência}

Apenas 10 respostas válidas de docentes e 8 de estudantes e deram informação sobre as formas que as IES e os professores encontraram de converter em atividades a distância as atividades de carácter prático, como aulas laboratoriais ou estágios.

Dois professores consideraram a adaptação impossível (Ex.: "Para práticas laboratório não é possível" R18). Também entre os estudantes, três respostas sinalizam a opção pelo adiamento dos estágios.

Oito professores dão conta da existência de uma mudança de estratégia, mas não apresentam geralmente informação muito concreta que permita compreender profundamente a natureza dessa mudança. Apenas um destes respondentes apresentou uma resposta mais explicativa, que incide sobre estágios de observação, em que se optou por atividades de carácter investigativo, a par do adiamento das horas de permanência física no contexto (R7). Este é um aspeto que carece de maior clarificação, eventualmente com recurso a entrevistas em profundidade.

Por sua vez, alguns estudantes indicam que o estágio foi dado por concluído ( 2 respostas, Ex: "Conclusão do estágio por realização de $85 \%$ das horas pedidas inicialmente" E36) e outros sinalizam práticas alternativas (4 respostas, Ex.: “substituição por casos clínicos” E4).

Outra das dificuldades que poderia colocar-se à transição para o ensino remoto é a resposta a estudantes com deficiência. Apenas quatro dos professores respondentes deram respostas a essa questão. Destes, três consideram que ocorreu uma migração para o online do apoio que já era proporcionado em situação presencial (Ex.: "Foi mantido o apoio que era dado a nível presencial, agora com os meios informáticos como suporte de contacto e comunicação" R17), e um considerou que o estudante com deficiência concreto que integrava a sua turma não necessitava de adaptações especiais nesta situação. Nenhum dos estudantes inquiridos referiu ter necessidades específicas que tivessem que ser acomodadas. Quer pelo reduzido número de respostas obtido, quer pela complexidade da situação, este é outro aspeto que consideramos carecer de maior aprofundamento.

\subsection{Dificuldades, constrangimentos e potencialidades}

\section{Dificuldades}

Os aspetos focados como principais dificuldades sentidas pelos docentes foram organizados em sete subcategorias, como se apresenta no quadro 1 abaixo. 


\section{Dialogia}

SEABRA, Filipa; AIRES, Luísa; TEIXEIRA, António. Transição para o ensino remoto de emergência no ensino superior em Portugal - um estudo exploratório

Quadro 1 - Subcategorias da categoria «dificuldades do professor»

\begin{tabular}{|c|c|c|}
\hline Subcategoria & $\begin{array}{l}\text { Frequência } \\
\text { (Respondentes) }\end{array}$ & Exemplo \\
\hline Gestão do tempo & 11 & "Falta de tempo"R19 \\
\hline Relações humanas & 6 & $\begin{array}{l}\text { "As aulas tornam-se mais expositivas e menos participadas, } \\
\text { especialmente com turmas grandes. Perde-se a partilha e o } \\
\text { debate, essencial em algumas aulas" R23 }\end{array}$ \\
\hline $\begin{array}{l}\text { Problemas } \\
\text { técnicos }\end{array}$ & 4 & $\begin{array}{l}\text { "Problemas técnicos de interação hardware/software } \\
\text { pontuais"R16 }\end{array}$ \\
\hline Mudança & 3 & "Assimilar a mudança" R32 \\
\hline Avaliação & 3 & $\begin{array}{l}\text { "dificuldades na adaptação dos elementos de avaliação } \\
\text { sumativa"R14 }\end{array}$ \\
\hline $\begin{array}{l}\text { Problemas } \\
\text { logísticos }\end{array}$ & 2 & "turmas demasiado grandes para fazer um ensino eficaz" R4 \\
\hline $\begin{array}{l}\text { Conceção do que é } \\
\text { a EaD }\end{array}$ & 1 & $\begin{array}{l}\text { "A confusão que existe subjacente ao que é educação a distância. } \\
\text { Havendo o equívoco de que é sinónimo de ensino online. A } \\
\text { exigência de aulas síncronas tem-se manifestado em } \\
\text { consideráveis níveis de cansaço" R26 }\end{array}$ \\
\hline
\end{tabular}

Fonte: Elaboração dos autores

\section{Constrangimentos}

Já os aspetos indicados pelos docentes como principais constrangimentos para os estudantes, organizaram-se em 9 categorias, conforme expresso no quadro 2:

\begin{tabular}{|c|c|c|}
\hline Subcategoria & $\begin{array}{l}\text { Frequência } \\
\text { (Respondentes) }\end{array}$ & Exemplo \\
\hline $\begin{array}{l}\text { Envolvimento dos } \\
\text { estudantes }\end{array}$ & 9 & $\begin{array}{l}\text { "A participação online durante as sessões de trabalhos das } \\
\text { turmas" R17 }\end{array}$ \\
\hline $\begin{array}{l}\text { Problemas } \\
\text { técnicos/ } \\
\text { tecnológicos }\end{array}$ & 7 & $\begin{array}{l}\text { "Dificuldades na utilização de alguns recursos tecnológicos" } \\
\text { R24 }\end{array}$ \\
\hline Falta de recursos & 5 & $\begin{array}{l}\text { "acesso a ferramentas tecnológicas (partilha de computador em } \\
\text { casa)"R30 }\end{array}$ \\
\hline Gestão do tempo & 5 & $\begin{array}{l}\text { "Dificuldades em gerir tarefas propostas em diferentes ucs." } \\
\text { R26 }\end{array}$ \\
\hline Avaliação & 4 & “ansiedade em relação à avaliação” R4 \\
\hline Adaptação & 2 & “adaptarem-se ao zoom” R27 \\
\hline $\begin{array}{l}\text { Interação com } \\
\text { professores e } \\
\text { colegas }\end{array}$ & 2 & $\begin{array}{l}\text { "viram-se isolados, em suas casas, a ter aulas exclusivamente a } \\
\text { distância, sem interacção presencial com professores e colegas." } \\
\text { R6 }\end{array}$ \\
\hline Não existem & 2 & $\begin{array}{l}\text { "Não têm surgido grandes constrangimentos da parte dos } \\
\text { estudantes" R12 }\end{array}$ \\
\hline $\begin{array}{l}\text { Exigência } \\
\text { excessiva dos } \\
\text { docentes }\end{array}$ & 1 & $\begin{array}{l}\text { "Demasiada exigência de alguns colegas que não percebem que } \\
\text { não podemos fazer TUDO como se estivesse a ser um tempo } \\
\text { "normal"' R18 }\end{array}$ \\
\hline
\end{tabular}

Fonte: Elaboração dos autores.

A perspetiva dos próprios estudantes sobre as principais dificuldades que enfrentam está expressa no quadro 3: 


\section{Dialogia}

SEABRA, Filipa; AIRES, Luísa; TEIXEIRA, António. Transição para o ensino remoto de emergência no ensino superior em Portugal - um estudo exploratório

Quadro 3 - Subcategorias da categoria «Constrangimentos dos estudantes» na perspetiva dos próprios estudantes

\begin{tabular}{|c|c|c|}
\hline Subcategoria & $\begin{array}{l}\text { Frequência } \\
\text { (Respondentes) }\end{array}$ & Exemplo \\
\hline $\begin{array}{l}\text { Excesso de } \\
\text { trabalho }\end{array}$ & 12 & $\begin{array}{l}\text { Muitos trabalhos para ler e resumir, com datas muito } \\
\text { aproximadas (E23) }\end{array}$ \\
\hline Gestão do tempo & 11 & $\begin{array}{l}\text { Conciliação do tempo entre atividades escolares e } \\
\text { responsabilidades familiares e domésticos. Pouco ou nenhum } \\
\text { tempo livre para lazer (E9) }\end{array}$ \\
\hline $\begin{array}{l}\text { Problemas } \\
\text { técnicos e } \\
\text { tecnológicos }\end{array}$ & 4 & $\begin{array}{l}\text { O zoom ter bastantes paragens e daí não ser possível ter uma } \\
\text { aula seguida (E32) }\end{array}$ \\
\hline $\begin{array}{l}\text { Interação com } \\
\text { professores e } \\
\text { colegas }\end{array}$ & 3 & $\begin{array}{l}\text { Falta de comunicação e dificuldade na realização dos trabalhos } \\
\text { em grupo, tendo em conta a distância (E22) }\end{array}$ \\
\hline $\begin{array}{l}\text { Falta de apoio } \\
\text { docente }\end{array}$ & 2 & $\begin{array}{l}\text { Falta de apoio. Alguns professores limitam-se a enviar textos e } \\
\text { trabalhos para executarmos e nem sequer nós dão aulas (E24) }\end{array}$ \\
\hline Tempo de ecrã & 2 & Muitas horas em frente ao computador (E34) \\
\hline Stress e ansiedade & 2 & $\begin{array}{l}\text { Adaptar a este novo método, e aguentar com a carga de } \\
\text { trabalhos e ainda ter que lidar com a situação do vírus (E37) }\end{array}$ \\
\hline $\begin{array}{l}\text { Acesso à } \\
\text { informação }\end{array}$ & 2 & O difícil acesso à biblioteca, mais precisamente, aos livros (E18) \\
\hline $\begin{array}{l}\text { Estágios e aulas } \\
\text { práticas }\end{array}$ & 1 & $\begin{array}{l}\text { O facto dos estágios e aulas práticas adaptadas não nos } \\
\text { fornecerem as aptidões necessárias para o exercício da nossa } \\
\text { profissão (E4) }\end{array}$ \\
\hline Avaliação & 1 & A incerteza da realização dos momentos de avaliação (E2) \\
\hline Não existem & 1 & Nenhuma (E1) \\
\hline
\end{tabular}

Fonte: Elaboração dos autores

Se o olhar dos professores recaía, em primeiro lugar, sobre questões tecnológicas e sobre o envolvimento dos estudantes, e só depois na gestão do tempo, o olhar dos estudantes salienta o papel desempenhado pelos professores - nomeadamente através da imposição de uma carga de trabalho sentida como excessiva - e da difícil gestão do tempo, e só secundariamente em questões tecnológicas e outras questões mais específicas. Estas respostas sinalizam a presença de dificuldades de adaptação ao ensino remoto, e de uma tendência para externalizar a responsabilidade por essas dificuldades.

\section{Potencialidades}

Por fim, e olhando agora para os aspetos que os professores identificaram como positivos ou com potencialidades em todo o processo, 20 respostas podem ser incluídas em sete subcategorias, como sistematizado no quadro 4. 


\section{Dialogia}

SEABRA, Filipa; AIRES, Luísa; TEIXEIRA, António. Transição para o ensino remoto de emergência no ensino superior em Portugal - um estudo exploratório

Quadro 4 - Subcategorias da categoria «Potencialidades e aspetos positivos», respostas dos docentes

\begin{tabular}{|c|c|c|}
\hline Subcategoria & $\begin{array}{l}\text { Frequência } \\
\text { (Respondentes) }\end{array}$ & Exemplo \\
\hline $\begin{array}{l}\text { Envolvimento dos } \\
\text { estudantes }\end{array}$ & 8 & $\begin{array}{l}\text { "maior assiduidade, responsabilidade e } \\
\text { compromisso/envolvimento com o estudo" R15 }\end{array}$ \\
\hline $\begin{array}{l}\text { Aumento da } \\
\text { proximidade }\end{array}$ & 7 & "Maior proximidade Professores/Estudantes" R15 \\
\hline $\begin{array}{l}\text { Novas } \\
\text { metodologias }\end{array}$ & 7 & $\begin{array}{l}\text { "maior criatividade na preparação de tarefas e instrumentos de } \\
\text { trabalho e de avaliação" R7 }\end{array}$ \\
\hline $\begin{array}{l}\text { Novas } \\
\text { aprendizagens }\end{array}$ & 4 & “Aprendi a usar recursos online para o apoio às aulas" R10 \\
\hline Gestão do tempo & 2 & “Autonomia e flexibilidade horária” R11 \\
\hline $\begin{array}{l}\text { Manutenção das } \\
\text { atividades }\end{array}$ & 2 & $\begin{array}{l}\text { "A possibilidade da manutenção das aulas, dos contactos com os } \\
\text { estudantes" R2 }\end{array}$ \\
\hline $\begin{array}{l}\text { Capacidade de } \\
\text { adaptação }\end{array}$ & 1 & $\begin{array}{l}\text { "A capacidade de adaptação da instituição a este processo de } \\
\text { transição abrupta e acelerada" R6 }\end{array}$ \\
\hline
\end{tabular}

Fonte: Elaboração dos autores.

Já os estudantes, salientam aspetos relacionados com as novas aprendizagens ou a conveniência, como expresso no quadro 5:

Quadro 5 - Subcategorias da categoria «Potencialidades e aspetos positivos», respostas dos estudantes

\begin{tabular}{|l|l|l|}
\hline Subcategoria & $\begin{array}{l}\text { Frequência } \\
\text { (Respondentes) }\end{array}$ & Exemplo \\
\hline $\begin{array}{l}\text { Modelo a manter } \\
\text { (em parte) }\end{array}$ & 6 & $\begin{array}{l}\text { o ensino a distância pode ser uma ótima ferramenta no entanto } \\
\text { as matérias e tarefas devem ser repensadas. Sugiro até que } \\
\text { algumas aulas passem a ser dadas a distância, podendo haver } \\
\text { aulas a distância e aulas presenciais. (E24) }\end{array}$ \\
\hline $\begin{array}{l}\text { Novas } \\
\text { aprendizagens }\end{array}$ & 6 & $\begin{array}{l}\text { O uso diário das tecnologias alargou os meus conhecimentos } \\
\text { nesta área (E28) } \\
\text { Conveniência deslocações aos trabalhadores estudantes (E11) }\end{array}$ \\
\hline $\begin{array}{l}\text { Flexibilidade } \\
\text { temporal }\end{array}$ & 5 & A flexibilidade na marcação de dias e horários das aulas (E18) \\
\hline $\begin{array}{l}\text { Maior apoio } \\
\text { docente }\end{array}$ & 3 & podemos interagir mais facilmente com os profs (E4) \\
\hline $\begin{array}{l}\text { Manutenção das } \\
\text { atividades }\end{array}$ & 2 & $\begin{array}{l}\text { Terem encontrado uma maneira de continuar dando suas aulas } \\
\text { dentro dos possíveis, dentro da normalidade (E30) }\end{array}$ \\
\hline $\begin{array}{l}\text { Maior } \\
\text { concentração }\end{array}$ & 2 & Não há distrações (E4) \\
\hline Não existem & 2 & Nenhuma (E1) \\
\hline
\end{tabular}

Fonte: Elaboração dos autores.

Nas respostas dos docentes, as questões ligadas à gestão do tempo foram as mais referidas como dificuldades dos docentes (11), mas também como constrangimentos percebidos em relação aos seus estudantes (5), e até mesmo, embora que com menor frequência, como vantagens ou potencialidades (2). Este parece ser assim um aspeto central a analisar e refletir em relação à adoção de estratégias de ERE mais sustentáveis. 
As questões relacionadas com o envolvimento dos estudantes também aparecem frequentemente referidas, quer como constrangimentos dos estudantes (9), quer como aspetos positivos ou potencialidades (8).

As questões relacionadas com as relações humanas, nomeadamente relações com colegas docentes e estudantes, são indicadas simultaneamente como um problema para os docentes (6); como um constrangimento para os estudantes (2), e como um ganho, abrangendo um aumento de proximidade entre professores e estudantes (5); entre docentes (4), e entre os próprios estudantes (2).

A gestão do tempo, o envolvimento dos estudantes, e as relações humanas parecem assim assumir papéis de charneira nas perspetivas apresentadas pelos docentes sobre os pontos mais críticos, mas também com maior potencial, desta experiência de ERE.

\section{Reflexões conclusivas}

O estudo revela a adoção de práticas pedagógicas muito díspares e diversas, reveladoras de um processo baseado em grande medida na iniciativa pessoal, e coordenado sobretudo ao nível da IES (SEABRA, AIRES, TEIXEIRA, 2020). Esta relativa descoordenação e aparente ausência de uma estratégia clara e de um modelo definido é compreensível, e compatível com ERE por oposição a práticas estruturadas de EaD (BOZCURT; SHARMA, 2020; HODGES; MOORE; LOCKEE; TRUST; BOND, 2020).

Denota-se, no geral, um sentimento moderadamente positivo sobre a forma como as IES deram continuidade ao ensino em face à situação de emergência com que se depararam, o que vem ao encontro dos resultados encontrados por Hewitt (2020). É exceção o sentimento de um forte aumento da carga de trabalho, relatada quer por professores, quer por estudantes - a gestão de tempo/carga laboral poderá ser um elemento fundamental para assegurar a sustentabilidade de iniciativas de ERE.

A avaliação é referida como aspeto fundamental, sendo muito focada como alvo das alterações ao processo no decurso do ERE, e como um dos seus constrangimentos, pelos professores.

Outro aspeto saliente dos resultados diz respeito às relações humanas (focadas quer como limitação, quer como potencialidade) que emergem nos resultados como aspeto a cuidar intencionalmente com vista ao sucesso do ERE (BOZKURT, SHARMA, 2020).

Por fim, assumimos as limitações do estudo, de natureza exploratória. Reconhecemos a necessidade de maior aprofundamento dos resultados encontrados, quer pelo acompanhamento 


\section{Dialogia}

SEABRA, Filipa; AIRES, Luísa; TEIXEIRA, António. Transição para o ensino remoto de emergência no ensino superior em Portugal - um estudo exploratório

das respostas que as IES continuam a dar a esta situação, quer pelo alargamento da recolha de dados, quer ainda por uma incidência particular em aspetos fundamentais e ainda insuficientemente esclarecidos, como sejam a forma como se encontrou resposta ao ensino de conteúdos de natureza prática, laboratorial ou em contexto de trabalho, e às necessidades particulares de estudantes com deficiência.

\section{Referências}

AERA. Code of ethics, Educational Researcher, v. 40, n. 3, p 145-156, 2011.

BATES, Tony. Re-defining online learning and distance education in 2020. Online Learning and Distance Education Resources, June $30^{\text {th }}$ 2020. Disponível em: https://www.tonybates.ca/2008/07/07/what-is-distance-education/. Acesso em: 28 set. 2020.

BOZCURT, Aras; SHARMA, Ramesh C. Emergency remote teaching in a time of global crisis due to CoronaVirus pandemic. Asian Journal of Distance Education, v. 14, n. 1, p. i-vi, 2020.

Disonível em:

https://www.researchgate.net/publication/341043562_Emergency_remote_teaching_in_a_time _of_global_crisis_due_to_CoronaVirus_pandemic. Acesso em: 28 set. 2020.

COPE, Bill; KALANTZIS, Mary. e-Learning ecologies: Principles for new learning and assessment. Routledge, 2017.

DANIEL, Teresa A. Application of a Systems Approach to Distance Education. Proceedings of the 50th Annual Meeting of the ISSS - 2006, Sonoma, CA, USA, 23 Jun. 2006. Disponível em: https://journals.isss.org/index.php/proceedings50th/article/view/274 . Acesso em: 28 set. 2020.

HEWITT, Rachel. Students' views on the impact of Coronavirus on their higher education experience. HEPI Policy Note, 24, Oxford: HEPI, 2020. Disponível em:

https://www.hepi.ac.uk/wp-content/uploads/2020/06/HEPI-Policy-Note-

24_Coronavirus_FINAL.pdf

HODGES, Charles; MOORE, Stephanie; LOCKEE, Barb; TRUST, Torrey; BOND, Aaron. The difference between emergency remote teaching and online learning. Educause review, $27^{\text {th }}$ March 2020. Disponível em: https://er.educause.edu/articles/2020/3/the-difference-betweenemergency-remote-teaching-and-online-learning . Acesso em: 28 set. 2020.

MOORE, Michael; KEARSLEY, Greg. Distance Education: A systems view of online learning. Belmont, CA: Thomson/Wadsworth, 2012.

MOORE, Michael G.; ANDERSON, William G. Handbook of distance education. Mahwah, NJ: Lawrence Erlbaum Associates, 2003.

PETERS, Otto. Distance education and industrial production: a comparative interpretation in outline. In: SEWART, David; KEEGAN, Desmond; HOLMEBERG, Börje (Eds.). Distance 


\section{Dialogia}

SEABRA, Filipa; AIRES, Luísa; TEIXEIRA, António. Transição para o ensino remoto de emergência no ensino superior em Portugal - um estudo exploratório

Education. International perspectives. London: Croom Helm, 1983. p. 95-113. Disponível em: http://www.c3l.uni-oldenburg.de/cde/found/peters67.htm Acesso em: 29 set. 2020.

SEABRA, Filipa; AIRES, Luísa; Teixeira, António. Transição de emergência para o online em universidades portuguesas no contexto de COVID-19: estudo exploratório. 8th International Congress of Educational Sciences and Development, Pontevedra, Espanha, 28-30 de outubro de 2020.

TAYLOR, James C. Fifth generation distance education. Higher education series, Camberra, report n. 40, p. 1-8, june 2001. Disponível em http:/ /www.c3l.uni-

oldenburg.de/cde/media/readings/taylor01.pdf Acesso em: 29 set. 2020.

Recebido em: 23 out. 2020/ Aprovado em: 19 nov. 2020

Cite como

(ABNT NBR 6023:2018)

SEABRA, Filipa; AIRES, Luísa; TEIXEIRA, António. Transição para o ensino remoto de emergência no ensino superior em Portugal - um estudo exploratório. Dialogia, São Paulo, n. 36, p. 316-334, set./dez. 2020. Disponível em: https://doi.org/10.5585/dialogia.n36.18545.

\section{American Psychological Association (APA)}

Seabra, F., Aires, L., \& Teixeira, A. (2020, set./dez.). Transição para o ensino remoto de emergência no ensino superior em Portugal - um estudo exploratório. Dialogia, São Paulo, 36, p. 316-334. https://doi.org/10.5585/dialogia.n36.18545. 